\title{
Comparison between Uses of Chlorhexidine Gluconate versus Povidone Iodine for Skin Preparation to Prevent Infection after Cardiothoracic Surgery
}

\author{
Nesma Shaker Said ${ }^{1}$, Amany Mohammed Sheble ${ }^{2}$ and \\ Hanan Abo-Bakr Mohammed ${ }^{3}$ \\ ${ }^{I}$ Nursing staff, Faculty of Nursing/ Mansoura University, Egypt \\ ${ }^{2}$ Prof.of Medical-Surgical Nursing, Faculty of Nursing/Mansoura University, Egypt \\ ${ }^{3}$ Lecturer of Medical Surgical Nursing, Faculty of Nursing/ Mansoura University, Egypt
}

\begin{abstract}
Surgical site infection is a kind of health care related infection which a wound illness occurs following to an invasive surgical process. Aim of study: Compare between using of chlorhexidine gluconate versus povidone iodine for skin preparation to avoid infection after cardiothoracic surgery. Setting of study: Cardio thoracic surgery department at Mansura University Hospital. Methods: Design: Quasi experimental designs comparative following up study. Subjects: 70patients were selected randomly and alternatively into two equivalent groups, 35 patients for every group. Tools: Two tools were used for study, Tool 1: Patients bio-sociodemographic data, contain of two parts, tool 2: Wound infection assessment: involved of 3 parts. Results: The most signs, symptoms and side effects of surgical site infection appeared in povidone group more than chlorhexidine group as well as there were organisms like staph auras presented in povidone group and no organisms presented in chlorhexidine group. Conclusions: the incidence of SSI with povidone iodine more than chlorhexidine group. Recommendations: chlorhexidine gluconate with alcohol should be used to prevent of SSI.
\end{abstract}

Key words: Skin Preparation, Infection, Cardiothoracic Surgery.

\section{Introduction}

A surgical site infection (SSI) is one of the most important causes of health care- associated infection. SSI is associated with considerable morbidity and it has been reported that over one third of postoperative deaths are related. SSI can double the length of time a patient stay in hospital and thereby increase costs of health care, the main additional costs are related to re-exploration, extra nursing care and intervention and drug treatment costs, the indirect costs due to loss of productivity, patient dissatisfaction and litigation and reduced quality of life ${ }^{(2)}$.

So as to reduce SSI should improving in infection control practices as operating room ventilation, sterilization, barriers for infection, following of the surgical aseptic techniques, and accessibility of antimicrobial prophylaxis for preoperative skin preparation

The use of preoperative skin preparation with proficient antiseptic plays an vital role in reducing postoperative wound infection. Topical antimicrobial skin preparation are intended to remove the transient flora and reduce the resident flora. It may be bacteriocidal otherwise bacteriostatic, their uses comprise cleansing of skin and wound surfaces subsequent to injury, preparation of skin surfaces preceding to injections or surgical operation, and Some commonly used antiseptics for skin cleaning includes chlorhexidine gluconate, povidone iodine compounds, and alcohol ${ }^{(11)}$.

Chlorhexidine gluconate $4 \%$ is generally used biocide as antiseptic and disinfectant products. It has broad spectrum efficacy and is much less irritating to tissue than other products. Chlorhexidine is greatly impaired in the existence of organic material. It is bactericidal and fungicidal to awide variety of organisms. It is antiviral activities are restricted to the lipid enveloped viruses such as rotavirus, hepatitis avirus, or poliovirus (17).

Povidone iodine $10 \%$ acting a rapidly bactericidal, fungicidal, tuberculocidal and sporicidal, although iodine have been used for 150 years as antiseptics, it have less reactive than chlorine, they are associated with irritation, extreme yellowing, in addition this type from antiseptic solutions are generally unstable besides it have at least seven species in a complex equilibrium, molecular iodine being responsible for antimicrobial efficiency primarily ${ }^{(3)}$. 


\section{Aim of the study}

Compare between using of chlorhexidine gluconate versus povidone iodine for skin preparation to avoid infection after cardiothoracic surgery.

\section{Research question}

Which antiseptics were efficient for controlling of SSI chlorhexidine gluconate 4\%with isopropyle alcohol $70 \%$ or povidone iodine $10 \%$ ?

\section{Operational definition}

Open heart surgery is surgical restore of the heart and the blood circulation which the chest is opened and surgery is prepared on the heart muscles, valves, arteries, there are many kinds of surgery like coronary artery bypass graft (CABG), mitral valve replacement (MVR), aortic valve replacement (AVR), atria sepal defect (ASD), ventricular sepal defect (VSD) and others (Leaper, 2010).

\section{Materials and method}

Design: A quasi experimental research design was utilized.

Setting: The study takes place at cardio thoracic surgery department at Main Mansura University Hospital.

Subjects: seventy cardiac patients were selected randomly, alternatively and devided into 2 groups agreed to participate in the study during a period from November 2014 to April 2015.

\section{Inclusion criteria:}

- Adult patients

- Agreed to participate

- Normal vital signs

- Schedulled for surgery of cardiothoracic

- No history of allergy to study agents

- Free from other disease as diabetes mellitus or immune-compromized disease

- Exclusion the following conditions such (unconscious patients, emergency conditions, patients with serum albumin less than $0.3 \mathrm{mg} / \mathrm{dl}$, patients with $\mathrm{HCV}$ or $\mathrm{HBV}$ ).

Tools:

Tool I- Patients bio-sociodemographic data: This tool was adopted from ${ }^{(29)}$ then modified by the researcher to evaluate patient bio-sociodemographic data it was divided of two parts:

Part 1: Socio-demographic data, it was used to gather information such as (age, sex, marital status, level of education, occupation or working).

Part 2: Patient's clinical information's as weight, height in addition to patient's habits like smoking, alcoholic use, exercise, diagnosis, previous surgeries, medications that had seen prescribed, past medical history such (Peripheral Arterial Occlusive Disease, hypertension, diabetes, cardiac obstructive pulmonary disease) History of Gastro Intestinal Tract bleeding or peptic ulcer that may influence of the platelets count after coronary artery revascularization and type of operation.

\section{Tool II- Wound infection assessment sheet:}

Part I of tool II was adopted from ${ }^{(23)}$ except amount of discharge- type of discharge, odor, color, consistency were adopted from ${ }^{(6)}$ and the researcher modified it to observe the signs and symptoms of patients with wound infection intended for seven days post operative it included three mains items as vital signs, localized pain and presence of drainage.

Part 1: Wound Assessment, this part was utilized to observe signs and symptoms of wound infection for seven days post operative it included three mains items as vital signs, localized pain and presence of drainage.

Part2: Laboratory Findings, the researcher utilized two specific diagnostic assessments to assess presence of wound infection for two groups like the following:

First: Two cultures were swapped from the patients as the following:

(1) First culture: Was taken from patient's skin first day before surgery.

(2) Second culture: Was taken from the wound at fifth day post surgery. 
Second: White blood cell and blood PH were assessed daily.

Part 3: This part was used to assess the side effect of antiseptic solutions for (povidone or chlorhexidine) for seven days after operation; it was compromised of two partitions as the next:

(3.1) Assessment of side effects that appeared after using of chlorhexidine gluconate $4 \%$ likes: skin irritation as well as itching, burning, rash of skin, and allergy.

(3.2) Assessment the side effects which occurred after using of povidone iodine $10 \%$ as signs of skin reactionsign of metabolic acidosis like drowsiness, weakness, headache, nausea plus vomiting, increase of respiratory rate as well as depth.

\section{Validity and Reliability}

\section{Method}

Validity of the tools were tested through a panel of five experts in the related fields one professors for medical and surgical nursing, and four assistants professors for medical and surgical nursing at the faculty of Nursing, Mansura University for clarity, relevance, comprehensiveness and simplicity.

The reliability of the developed tools were tested using the Cronbach's alpha test to measure the internal consistency of the tools (alpha $=0.86 \%$ ).

\section{Pilot study}

Was done on $10 \%$ of cases (7 patients) whom didn't incorporated in the actual study to test applicability of the developed tool, feasibility and necessary modifications were be carried out.

\section{Field Work}

The researcher interviewing the cardiac patients presented at department individualized few days before operation then explains for the patient process of skin preparation (hair cut, showering and skin sterilization) and its significance for preventing of SSI. Then verbal consent approval was obtained from each patient in the study. The activity took place in cardio thoracic department at Mansura University Hospitals. The data were together at the period of 6 months from November 2014 to April 2015. The researcher performed skin preparation in three procedures as (hair cut, showering and skin disinfectant) as the following:

1. Hair removal: Hair removal occurred at night before operation after explain the procedure for patients and taken verbal permission from them and used clippers by way of reusable handle and disposable slide, the researcher used clipper for hair removal from chest and abdominal patients stroke in opposite to the direction that the hair is growing via using short strokes, razor shaves wasn't recommended.

2. Showering: The researcher advised patients to showering twice before the operation, the first showering might be the night before the operation after hair removal and the second showering at 15 minutes before the operation used the antiseptic solution as povidone iodine during showering for control group and used chlorhexidine gluconate during showering for study group.

3. Skin sterilization: The researcher sterilized the skin before taking the first culture from the incision site to peripherally, the area to be prepped includes from the top of the shoulder to below the diaphragm and from upper arms to elbow circumferentially and to the axilla. The first culture taking from the incision site after skin sterilization with antiseptic solutions and second culture taking from

\section{Ethical Consideration} the wound at $5^{\text {th }}$ day of operation after clean the wound with normal saline.

Official approval to carry out the study was get on from faculty of nursing to the directors of Mansura University and for cardio thoracic department at Mansura university hospital based on official letter from faculty of nursing including the title, aim and duration of the study.

Informed consent was taken from the patient's who participated in the study after explanation of the purpose of the study, voluntary participation was assured as they were given an opportunity to refuse the participation and they were ascertained that there information would be used only for research purposes. Confidentiality and privacy of the patients were assured.

\section{Statistical analysis}

The data was revised after it had collected, and so it was coded then fed to statistical software IBM SPSS version 20. The known graphs were revealed via using Microsoft excel software.Every one of statistical analysis was made by using two tailed tests and alpha error of 0.05 . $\mathrm{P}$ value less than or equal to 0.05 was measured to be statistical significantly.

\section{Results}

Table (1): Shows the mean age of patients in both groups were $(41.1 \pm 9.6)$. The majority of patients of both groups were male and married, in relation to body weight the largest proportions of both groups were obese, according to patient habits less than half of both groups were smoking. 
Figure (1): This figure clarified that the rate of infection at $7^{\text {th }}$ day in povidone group more than chlorhexidine group since WBCs in povidone group more than normal range while it were with normal rate in chlorhexidine group.

Figure (2): This figure shown that common organisms appeared in both groups at $1^{\text {st }}$ day were staph epidermis and staph aureus.

Figure (3): Staph aureus was the most common organisms appeared in povidone group at $5^{\text {th }}$ day, while the majority of chlorhexidine group had no growth microbial.

Table2: This table shows that there were no side effects appeared with chlorhexidine for seven days.

Table 3: The majority of povidone group taking place side effects in $3^{\text {th }}$ day and $7^{\text {th }}$ day as HTN, skin rash, itching, hotness, redness, fatigue, weakness, headache, nausea, vomiting.

Table 1: Percentage distribuation of patients according to bio- sociodemographic characteristics.

\begin{tabular}{|c|c|c|c|c|c|}
\hline \multirow{3}{*}{ Demographic data } & \multicolumn{4}{|c|}{ Groups } & \multirow{3}{*}{$M C P$} \\
\hline & \multicolumn{2}{|c|}{ Povidone Iodine } & \multicolumn{2}{|c|}{ Chlorhexidinegluconate } & \\
\hline & No & $\%$ & No & $\%$ & \\
\hline \multicolumn{5}{|l|}{ Age (years) } & \multirow{5}{*}{$0.001 *$} \\
\hline - $20-$ & 4 & 11.4 & 5 & 14.3 & \\
\hline - $30-$ & 12 & 34.3 & 14 & 40.0 & \\
\hline - $40-$ & 1 & 2.9 & 16 & 45.7 & \\
\hline - $50+$ & 18 & 51.4 & 0 & 0.0 & \\
\hline - $\quad$ Mean \pm SD & \multicolumn{2}{|c|}{$44.4 \pm 10.6$} & \multicolumn{2}{|c|}{$38.1 \pm 8.9$} & \\
\hline - $\quad$ Overall Mean \pm SD & \multicolumn{4}{|c|}{$41.1 \pm 9.6$} & \\
\hline \multicolumn{5}{|l|}{ Gender } & \multirow{3}{*}{$0.092 !$} \\
\hline - Male & 16 & 45.7 & 23 & 65.7 & \\
\hline - Female & 19 & 54.3 & 12 & 34.3 & \\
\hline \multicolumn{5}{|l|}{ Marital status } & \multirow{4}{*}{0.439} \\
\hline - Single & 3 & 8.6 & 5 & 14.3 & \\
\hline - $\quad$ Married & 32 & 91.4 & 29 & 82.9 & \\
\hline - Divorced & 0 & 0.0 & 1 & 2.9 & \\
\hline \multicolumn{5}{|l|}{ Education level } & \multirow{6}{*}{0.161} \\
\hline - Illiterate & 10 & 29.4 & 4 & 11.4 & \\
\hline - $\quad$ Read \& Write & 15 & 44.1 & 18 & 51.4 & \\
\hline - Secondary & 7 & 20.6 & 8 & 22.9 & \\
\hline - University & 1 & 2.9 & 5 & 14.3 & \\
\hline - Others & 1 & 2.9 & 0 & 0.0 & \\
\hline Occupation & & & & & \multirow{3}{*}{0.676 ! } \\
\hline - Working & 11 & 32.4 & 13 & 37.1 & \\
\hline - Not working & 23 & 67.6 & 22 & 62.9 & \\
\hline \multicolumn{5}{|l|}{ BMI } & \multirow{4}{*}{0.108} \\
\hline - Normal weight & 4 & 11.4 & 1 & 2.9 & \\
\hline - Overweight & 13 & 37.1 & 8 & 22.9 & \\
\hline - Obese & 18 & 51.4 & 26 & 74.3 & \\
\hline \multicolumn{5}{|l|}{ Patient habits } & \multirow{5}{*}{0.104} \\
\hline - $\quad$ No & 9 & 25.7 & 8 & 22.9 & \\
\hline - $\quad$ Smoking & 17 & 48.6 & 13 & 37.1 & \\
\hline - Exercises & 6 & 17.1 & 3 & 8.6 & \\
\hline - $\quad$ Special diet & 3 & 8.6 & 11 & 31.4 & \\
\hline
\end{tabular}

MCP: Mont Carlo exact probability !: Fisher exact probability* $\mathrm{P}<0.05$ (significant) 


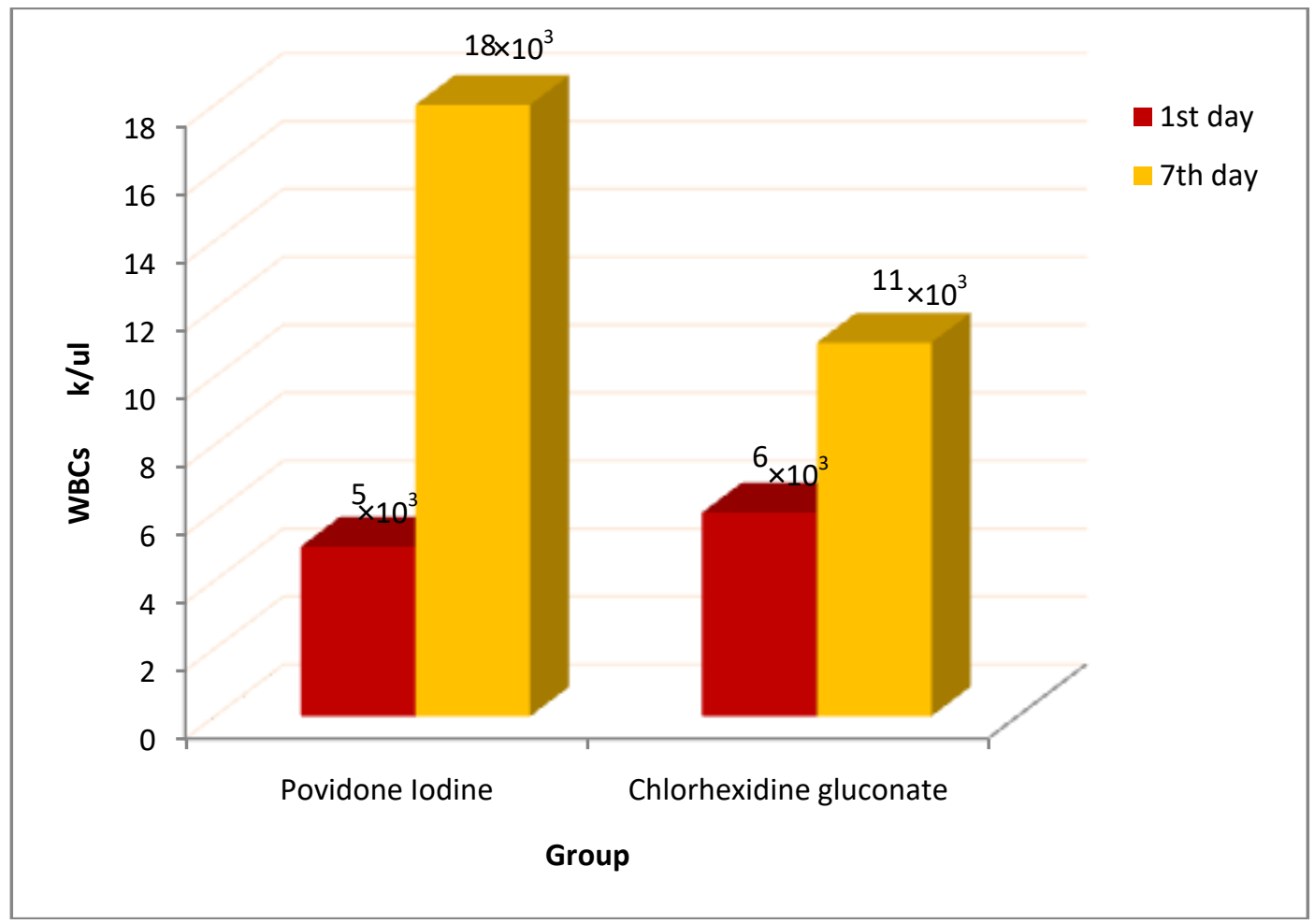

Figure (1): Level of WBCs at $1^{\text {st }}$ preoperative and $7^{\text {th }}$ day post operative for two groups.

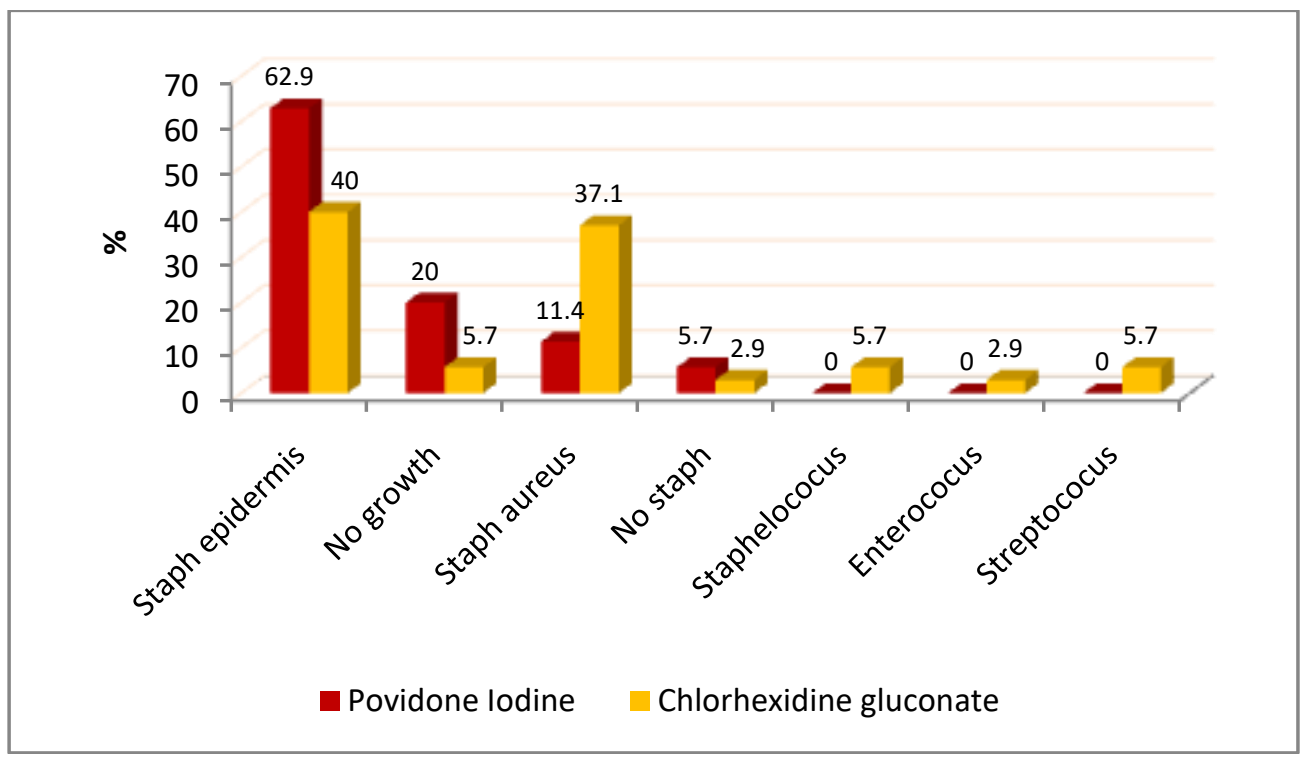

"Fig2": First culture from skin of patient before the operation for both groups. 


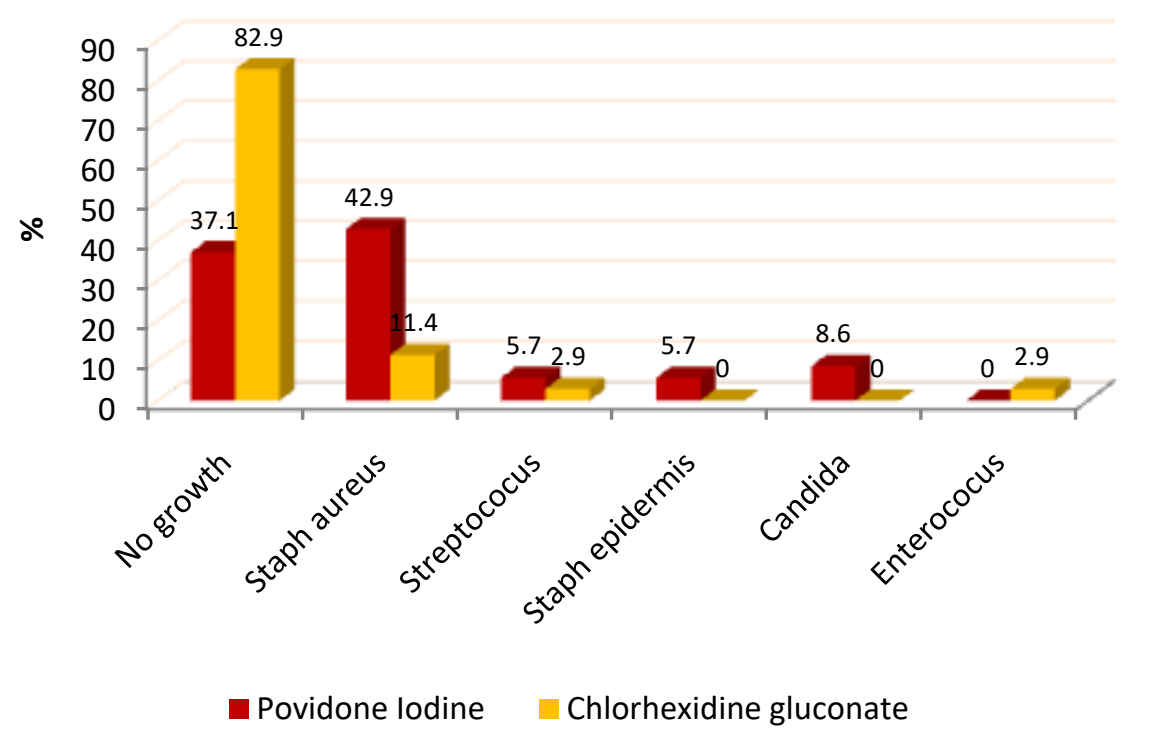

"Fig 3" Second culture from the wound post surgery for two groups.

Table2: Percentage distribution of patients according to side effect of chlorhexidine gluconate at $3^{\text {rd }}$ and $7^{\text {th }}$ day of operation.

\begin{tabular}{|c|c|c|c|c|c|c|}
\hline \multirow{2}{*}{\multicolumn{2}{|c|}{ Side effects }} & \multicolumn{4}{|c|}{ Chlorhexidinegluconate } & \multirow{3}{*}{$\mathbf{P}_{\mathrm{mc}}$} \\
\hline & & \multicolumn{2}{|c|}{ 3rd day post surgery } & \multicolumn{2}{|c|}{ 7th day post surgery } & \\
\hline & & No & $\%$ & No & $\%$ & \\
\hline \multirow{2}{*}{ Skin irritation } & - Yes & 2 & 5.7 & 4 & 11.4 & \multirow{2}{*}{0.251} \\
\hline & - $\quad$ No & 33 & 94.3 & 31 & 88.6 & \\
\hline \multirow{2}{*}{ Blistering } & - $\quad$ Yes & 2 & 5.7 & 3 & 8.6 & \multirow{2}{*}{0.854} \\
\hline & - $\quad$ No & 33 & 94.3 & 32 & 91.4 & \\
\hline \multirow{2}{*}{ Burning } & - Yes & 1 & 2.9 & 1 & 2.9 & \multirow{2}{*}{1.000} \\
\hline & - $\quad$ No & 34 & 97.1 & 34 & 97.1 & \\
\hline \multirow{2}{*}{ Itching } & - $\quad$ Yes & 2 & 5.7 & 4 & 11.4 & \multirow{2}{*}{0.085} \\
\hline & - $\quad$ No & 33 & 94.3 & 31 & 88.6 & \\
\hline \multirow{2}{*}{$\begin{array}{c}\text { Swelling in hand and } \\
\text { face }\end{array}$} & - Yes & 0 & 0.0 & 0 & 0.0 & \multirow[t]{2}{*}{-} \\
\hline & - $\quad$ No & 35 & 100.0 & 35 & 100.0 & \\
\hline \multirow{2}{*}{ Skin rash } & - $\quad$ Yes & 1 & 2.9 & 1 & 2.9 & \multirow{2}{*}{1.000} \\
\hline & - $\quad$ No & 34 & 97.1 & 34 & 97.1 & \\
\hline \multirow[b]{2}{*}{ Peeling } & - $\quad$ Yes & 1 & 2.9 & 1 & 2.9 & \multirow[b]{2}{*}{1.000} \\
\hline & - No & 34 & 97.1 & 34 & 97.1 & \\
\hline \multirow{2}{*}{ Allergies } & - $\quad$ Yes & 0 & 0.0 & 0 & 0.0 & \\
\hline & - $\quad$ No & 35 & 100.0 & 35 & 100.0 & \\
\hline
\end{tabular}

$\mathrm{P}_{\mathrm{mc}}: \mathrm{P}$ value of Mc-Nemar test

Table 3: Percentage distribution of patients according to side effects of povidone iodine at $3^{\text {rd }}$ dayand $7^{\text {th }}$ day of operation.

\begin{tabular}{|c|c|c|c|c|c|c|}
\hline \multirow{3}{*}{\multicolumn{2}{|c|}{ Side effects }} & \multicolumn{4}{|c|}{ Povidone Iodine } & \multirow{3}{*}{$\mathbf{P} \mathrm{R}_{\mathrm{mc}}$} \\
\hline & & \multicolumn{2}{|c|}{$\begin{array}{l}\text { 3rd day post } \\
\text { surgery }\end{array}$} & \multicolumn{2}{|c|}{ 7th day post surgery } & \\
\hline & & No & $\%$ & No & $\%$ & \\
\hline \multirow{2}{*}{ Skin rash } & - Yes & 25 & 71.4 & 31 & 88.6 & \multirow{2}{*}{0.214} \\
\hline & - $\quad$ No & 10 & 28.6 & 4 & 11.4 & \\
\hline \multirow{2}{*}{ Itching } & - Yes & 32 & 91.4 & 32 & 91.4 & \multirow{2}{*}{1.000} \\
\hline & - $\quad$ No & 3 & 8.6 & 3 & 8.6 & \\
\hline
\end{tabular}




\begin{tabular}{|c|c|c|c|c|c|c|}
\hline Redness & $\begin{array}{ll}\text { - } & \text { Yes } \\
\text { - } & \text { No }\end{array}$ & $\begin{array}{l}24 \\
11\end{array}$ & $\begin{array}{l}68.6 \\
31.4\end{array}$ & $\begin{array}{l}24 \\
11\end{array}$ & $\begin{array}{l}68.6 \\
31.4\end{array}$ & 1.000 \\
\hline \multirow{2}{*}{ Hotness } & - Yes & 19 & 54.3 & 11 & 31.4 & \multirow{2}{*}{0.475} \\
\hline & . $\quad$ No & 16 & 45.7 & 24 & 68.6 & \\
\hline \multirow{2}{*}{ LL edema } & - Yes & 13 & 37.1 & 13 & 37.1 & \multirow{2}{*}{1.000} \\
\hline & - No & 22 & 62.9 & 22 & 62.9 & \\
\hline \multirow{2}{*}{ HTN } & - Yes & 19 & 54.3 & 19 & 54.3 & \multirow{2}{*}{1.000} \\
\hline & - $\quad$ No & 16 & 45.7 & 16 & 45.7 & \\
\hline \multirow{2}{*}{ Fatigue } & - Yes & 26 & 74.3 & 20 & 57.1 & \multirow{2}{*}{0.351} \\
\hline & - $\quad$ No & 9 & 25.7 & 15 & 42.9 & \\
\hline \multirow{2}{*}{ Vomiting } & - Yes & 17 & 48.6 & 10 & 28.6 & \multirow{2}{*}{0.308} \\
\hline & - $\quad$ No & 18 & 51.4 & 25 & 71.4 & \\
\hline \multirow{2}{*}{ Diarrhea } & - Yes & 10 & 28.6 & 15 & 42.9 & \multirow{2}{*}{0.142} \\
\hline & - $\quad$ No & 25 & 71.4 & 20 & 57.1 & \\
\hline \multirow{2}{*}{ Oral ulcers } & - Yes & 5 & 14.3 & 15 & 42.9 & \multirow{2}{*}{$0.025^{*}$} \\
\hline & - No & 30 & 85.7 & 20 & 57.1 & \\
\hline \multirow{2}{*}{ Thirst } & - Yes & 17 & 48.6 & 25 & 71.4 & \multirow{2}{*}{$0.009 *$} \\
\hline & - No & 18 & 51.4 & 10 & 28.6 & \\
\hline \multirow{2}{*}{ Dry swollen } & - Yes & 19 & 54.3 & 16 & 45.7 & \multirow{2}{*}{0.321} \\
\hline & - No & 16 & 45.7 & 19 & 54.3 & \\
\hline \multirow{2}{*}{ Sticky mucus } & - Yes & 11 & 31.4 & 13 & 37.1 & \multirow{2}{*}{0.471} \\
\hline & - $\quad$ No & 24 & 68.6 & $22 \mathrm{~T}$ & 62.9 & \\
\hline \multirow{2}{*}{$\begin{array}{c}\text { Flushed } \\
\text { membranes }\end{array}$} & - Yes & 13 & 37.1 & 16 & 45.7 & \multirow{2}{*}{0.524} \\
\hline & - $\quad$ No & 22 & 62.9 & 19 & 54.3 & \\
\hline \multirow{2}{*}{ Weakness } & - Yes & 29 & 82.9 & 33 & 94.3 & \multirow{2}{*}{0.328} \\
\hline & - $\quad$ No & 6 & 17.1 & 2 & 5.7 & \\
\hline \multirow{2}{*}{ Headache } & - Yes & 25 & 71.4 & 20 & 57.1 & \multirow{2}{*}{0.204} \\
\hline & - No & 10 & 28.6 & 15 & 42.9 & \\
\hline \multirow{2}{*}{ Drowsiness } & - Yes & 19 & 54.3 & 24 & 68.6 & 0624 \\
\hline & - $\mathrm{No}$ & 16 & 45.7 & 11 & 31.4 & 0.024 \\
\hline Tochunno & - Yes & 20 & 57.1 & 17 & 48.6 & 0.452 \\
\hline 1acnyponed & - $\mathrm{No}$ & 15 & 42.9 & 18 & 51.4 & $0.4 J 2$ \\
\hline Nausea/vomitig & - Yes & 22 & 62.9 & 21 & 60.0 & 0.869 \\
\hline & - $\quad$ No & 13 & 37.1 & 14 & 40.0 & \\
\hline
\end{tabular}

$\mathrm{PR}_{\mathrm{mc}} \mathrm{R}: \mathrm{P}$ value of Mc-Nemar test* $\mathrm{P}<0.05$ (significant)

\section{Discussion}

Surgical site infections (SSI), is one of the most important causes of health care- associated infection. SSI is associated with considerable morbidity and it has been reported that over one third of postoperative deaths are related. SSI can double the length of time a patient stay in hospital and thereby increase costs of health care, the main additional costs are related to re-exploration, extra nursing care and intervention and drug treatment costs, the indirect costs due to loss of productivity, patient dissatisfaction and litigation and reduced quality of life, ${ }^{(4)}$.

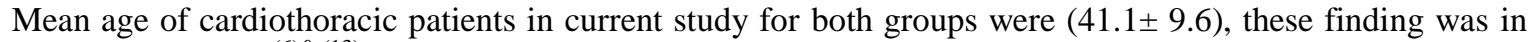
line with the study of, ${ }^{(6) \&(13)}$ that clarified that mean age of cardiac patients was $(41.1 \pm 7.3)$, while this study was contrast with study of, ${ }^{(20)}$. stated that mean age of cardiothoracic patients were $(71.0 \pm 15)$.

Gender at cardiothoracic were the majority of patients in our study for two groups were male this results were accepted with study of, ${ }^{(12)}$ clarified in his study about cardio vascular disease are the most common diagnosis for cardiac patient were males while this results differ from study of, ${ }^{(9)}$ said in their study about coronary artery disease that more than half of cardiac patient were females.

Marital status at cardiothoracic patients, ${ }^{(18)}$ reported that the majority of cardiac patients were married, this results were supported with the researcher which clarified in his study that the majority of both groups were married, while it were contrast with study of ${ }^{(12)}$ shown that most of cardiac patients were unmarried. 
White blood cells in povidone group increased from $1^{\text {st }}$ day to $7^{\text {th }}$ day this means that infection occurred in this group, this study were in line with study of, ${ }^{(19)}$ revealed that surgical site infection lead to elevation of WBCs also study of, ${ }^{(23)}$ approved that wound infection associated with increasing of WBCs, while this study differ from, ${ }^{(1)}$ approved that wound infection not associated with increasing of WBCs. According to chlorhexidine group contain normal range of WBCs from $1^{\text {st }}$ day to $7^{\text {th }}$ day this means that no infection occurred in chlorhexidine group.

The common organisms appeared in povidone and chlorhexidine groups at $1^{\text {st }}$ day were staph epidermis and staph aureus this results were accepted with study of, ${ }^{(29)}$ emphasized that staph epidermis was the commonest microorganism present on skin, and there were other result, ${ }^{(1)}$ reported that staph aureus was the most common organism on human skin, on the other hand this results disagree with, ${ }^{(21)}$ clarified that staphylococcus the most organism appeared on normal skin, ${ }^{(19)}$ illustrated that majority of human skin carry on candida.

At $5^{\text {th }}$ day staph auras appeared in less than half of povidone group while majority of chlorhexidine groups had no growth, this results accept with, ${ }^{(10)}$ concluded that chlorhexidine had positive effect as antiseptics solution than povidone iodone,this results accepted with study of, ${ }^{(3)}$ approved that chlorhexidine eliminate wound infection than povidoneiodone,

Study of, ${ }^{(29)}$ discussed the effect of chlorhexidine versus povidoneiodone approved that chlorhexidine was superior for povidone iodine, and study of, ${ }^{(26)}$ used on their in his research chlorhexidine and povidone iodone and found that chlorhexidine was more effective for wound protection than, also study of, ${ }^{(10)}$ clarified that chlorhexidine better than povidone iodone for preclusion of SSI, it disagree with, ${ }^{(32)}$ concluded that povidone iodone enhanced than chlorhexidine for infection prevention.

It was noticed from the present study that the commonest side effect appeared in povidone group only and no side effects appeared in chlorhexidine group. This results were agreement, ${ }^{(3)}$ reported that there were side effects for the use of povidone group and suggested that health care workers should be used it cautionary also study of, ${ }^{(26)}$ shown that used povidone iodone caused skin allergy, irritation, weakeness, drowsiness.

A study done by ${ }^{(3)}$ shown that used povidoneiodone caused skin allergy, irritation, weakeness, drowsiness, tachypnea headache, in addition to, ${ }^{(32)}$ clarified that using of povidone iodone caused itching, redness, nausea, vomiting, headache, shin allergy, hypertension, besides to study done by, ${ }^{(29)}$ found that povidone iodone caused anorexia, redness, diarrhea, itching, irritation, oral ulcer.

Study of, ${ }^{(22)}$ said that chlorhexidine was preferable and didn't cause any side effect, also this results were on line with, ${ }^{(29)}$ clarified that chlorhexidine was a good antiseptic solutions and free from any side effects, also study of, ${ }^{(25) \&(17)}$ revealed that chlorhexidine was more effective for wound and didn't cause side effects. As well as study of ${ }^{(26)}$ illusterated that chlorhexidine was a better antiseptic solutions and didn't cause any side effects. On contrary study of, ${ }^{(19)}$ shown that povidone iodine was proficient and have not side effect and study of ${ }^{(3)}$ found that chlorhexidine lead to skin allergy.

\section{Recommendations}

1. Using of chlorhexidine gluconate in hospitals rather than povidone iodone.

2. A replication of the study should be done using other solutions than povidone iodone with a large probability sample from different geographical area to attain more generalization of the results.

\section{References}

[1]. G. Abdel Hady, M. Abdel Wahab, O.EL Gilany, M. Ghoneim, and A. khashaba, Nosocomial Infection Surveillance in an Egyptian Intensive Care Units. Journal of Hospital Infection; 83 (3), 2013,196-19 9.

[2]. M. Abdel Haleim, E. El-Tah, Z. Ibrahim, Surgical site infections and Associated Risk Factors in Egyptian Orthopedic Patients. American Journal of Sci; 6, 2010, 272 -280.

[3]. M. Adler, K. Bishop,K. Brigger, and J. Mastrobattista, Comparison of Bactericidal Properties of Alcohol-Based Chlorhexidine versus Povidone- Iodine prior to Amniocentesis. American Journal of Perinatol; (29), 2013, 455-458.

[4]. Andrew Welsh, National collaborating Centre for women's and children's health. $1^{\text {st }}$ (Surgical site infection prevention and treatment.london, 2008), 1-97.

[5]. G. Bain, R. Foster, H. Kuwahata, B. Raymond, 2005, Tea Tree / Hydro Gel Dressing Used in Wound Care. Rural Industeries Research and Development Corporation Available at:http://www. rirdc. Gov. au/reports /TTO/05-114. Accessed on April 7, 2014.

[6]. Barbara Bates -Jensen.Cannie Harris., Nancy Parslow., Rose Raizman, development of pictorial guide for training nurses. Wound assessment tools. Wound care Canada.7 (2), 2009, 33-38.

[7]. Barbara K.Timby, Nancy E. Smith, Introductory Medical-Surgical Nursing, 10 (Philadelphia, Lippincott Williams \&Wilkins, 2010) , $147,148,405$.

[8]. S.H. Bhatty, R. Cooke, R. Shetty, and I. Jovin, Vascular Access Complications: Diagnosis and Management, Current Treatment Options in Cardiovascular Medicine; 3. (4), 2013, 503-514.

[9]. I. Bullock, D. Clark, J.O. Malone, Adult Nursing Practice; Using Evidence in Care. United Kingdom, Oxford University Press, 2012 93-97.

[10]. M. Carrick M., R. Darouiche R.,H. Itani K., Otterson F., Wall J., WebbA., Chlorhexidine- Alcohol versus Povidone- Iodine for Surgical- Site Antisepsis. England Journal Med, 2010, 362: 18 -26. 
[11]. Dumville JC., Edwards P, preoperative skin antiseptics for prevent surgical wound infection after clean surgery. Cochrane database systemic Rev.(3), .2013 cd 003949.

[12]. J. Elizabeth, Bridges, S. Erika, Sivarajan, Froelicher, Sandra Adams Motzer, L, Susan, Cardiac Nursing, 6 (Philadelphia Lippincott Publication, 2010), 462, 595, 612

[13]. A. Francesco, D. Nicolini, S. Fortuna, pikka, Cardiothoracic surgery. Gender differences in outcomes following isolated coronary artery bypass.USA, 2016, 11-144.

[14]. D. Ignatavicius., M. Workman, Medical- Surgical Nursing: Patient-Centered Collaborative Care. 7(United States of America. Elsevier Saunders Co, 2013), 686-705.

[15]. A. Jeremias, D. Brown, Cardiac Intensive Care. 2(Philadelphia. Elsevier Saunders., 2010), 559-563.

[16]. D. Leaper, leading article. Surgical site infection. British journal surgical. 97(22), 2010, 1601-1605.

[17]. I. Lee, R. Agarwal, systematic review and cost analysis comparing use of chlorhexidine gluconate with use of iodine for preoperative skin antisepsis to prevent SSI. Infect control Hosp epidemiol. 31(12), 2010, 1219- 1229.

[18]. S. Lipsky, M. Bohnen, J. Barnhart, The Impact of Sociodemographic Factors on Knowledge of Cardiac Procedures, Scientific Research, 1, 2010, 229-232.

[19]. C. MC Donald, B. Coignard, E. Dubberke, T. Horan, Infection control epidemiology. Recommendations for surveillance of clostridium difficile. Associated disease. 28, 2015, 140-145.

[20]. D. Moser, B. Riegel, Cardiac Nursing. 12 (Canada. Elsevier Saunders Co, 2008), 339-343.

[21]. V. Paocharoen, C. Mingmalairak, A. Apisarnthanarak, comparison of surgical wound infection after preoperative skin preparation with 4\% chlorhexidine and povidone iodine, Aprospective randomized trail. Journal medicine.92(7), $2009,898-902$.

[22]. R.A. Patil, V. Gaikwd, R.M. Kulkami, comparative study of chlorhexidine- alcohol versus povidone iodine for surgical site antisepsis in clean, clean contaminated cases. J med Thesis 1 (1), 2013, 33-34.

[23]. D. Penwarden, C. Montgomery, protocol for obtaining blood cultures from central venous catheters and peripheral sites. Clinical microbial infection. 8(1), 2005, 290-294.

[24]. C. Piva, E. Vaz, M. Moraes, S. Goldmeyer, G. Linch, G. Nogueira, D. Souza, (2014): Discomfort Reported by Patients After Cardiac surgeries, RevistaBrasileira de CardiologiaInvasiva, 22(1), 2014, 36-40.

[25]. H. RicharD, Use Chlorhexidine Gluconate for Skin Care Journal Watch General Medicine; 14 (6), 2008,25 -27.

[26]. A. Rodrigues, M. Simoes, incidence of SSI with preoperative skin preparation using $10 \%$ povidone iodine and 5\% chlorhexidine alcohol. Rev col Bras cir. 40(6), 2013, 443- 448.

[27]. M. Sandra, N. Bojar, Lippincott Manual of Perioperative Care in Adult Cardiac Surgery, 5 (United Kingdom, Blackwell Publishing,2011), 404.

[28]. M. Shabrawi, Frequency and risk factors of vascular complications following coronary procedures. MSC Thesis, Faculty of Medicine, Ain Shams University, 2010.

[29]. M.W. Soheir, M. E. Aml, Z. L. Aza, E.F. Manal, E.E. Shaimaa, 2011, The Effect of ChlorhexidineGluconate versus Povidone Iodine on Occurance of Centeral Venous Catheter Infection. by Using The Website;WWW.DSS Research.Com. Accessed on; May 5,2014 .

[30]. M. Susane, N. Pear, Best practice for SSI. Managing infection control, risk factor for SSI prevention. USA, 2012, 57-62.

[31]. Y. Takesue, A. Watanabe, H. Hanaki, nationwide survillence of antimicrobial susceptibility patterns pathogens isolated from SSI. Japan.journal infection chemother. 18(6), 2012, 816-826.

[32]. S. Tschudin. D. Suttere, Y. Freir, W. Egli, E. Gany, Risk of SSI from residual bacterial after disinfection with povidone iodone alcohol.255(3), 2012, 565-569. 